\title{
Estimation of indirect reference intervals for serum thyrotropin using hospital records
}

\author{
Kushal Bhattarai', Nilu Manandhar ${ }^{2}$, Prabodh Shrestha ${ }^{3}$, Sangita Thapa ${ }^{4}$, Jharana Shrestha ${ }^{5}$, \\ Goma Kathayat ${ }^{6}$, Reshma Shrestha ${ }^{7}$, Suman Kafle ${ }^{8}$, Athokpam Rajendra Singh ${ }^{9}$ \\ ${ }^{1,5}$ Lecturer, ${ }^{9}$ Associate Professor, $4,6,7,8$ Post-graduate Resident, Department of Biochemistry, College of Medical \\ Sciences and Teaching Hospital, ${ }^{2}$ Lecturer, Department of Physiology, College of Medical Science and Teaching \\ Hospital, ${ }^{3}$ Laboratory In-charge, Department of Laboratory Medicine, College of Medical Sciences, and Teaching \\ Hospital, Bharatpur, Chitwan, Nepal
}

Background: Reference intervals of any biochemical analyte serve as an invaluable tool in clinical decision making. The IFCC (International Federation of Clinical Chemistry) guidelines for determining these values are not feasible in some hospital laboratory settings and have led to the development of alternative approaches. Aims and Objectives: To determine the indirect reference intervals for serum thyrotropin from the hospital records of individuals visiting a tertiary care center. Materials and Methods: In a hospital-record based, observational, cross-sectional study, data of serum TSH levels were collected from the hospital records of participants who underwent this test in the Central Clinical Laboratory, College of Medical Sciences and Teaching Hospital, Bharatpur, Chitwan, Nepal from July 2012 to June 2015. All the individuals, irrespective of their diagnoses of thyroid diseases and other possible comorbid conditions, were included in the study. Prior to the statistical analyses, partitioning was done in relation to gender, age, and ethnicity. The reference intervals for thyrotropin were established by non-parametric method. Results: Reference intervals for serum TSH best agreeing to those provided by the test kit suppliers were determined by combining the two strategies that used Tukey's method of detection and removal of outliers, prior to the final analyses. Lower limit was best determined from the natural-log-transformed and upper limit from non-transformed TSH values with outliers removed by Tukey's method in both. As such, for the cases with TSH in the range 0.02-98.8 $\mathrm{mIU} / \mathrm{L}$, the reference intervals were calculated as $[0.31(0.30-0.33)$ to $6.04(5.97-6.12) \mathrm{mIU} / \mathrm{L}]$ and for the TSH in the range $0.102-9.99 \mathrm{mIU} / \mathrm{L},[0.35(0.34-0.37)$ to $5.81(5.75-5.90) \mathrm{mlU} / \mathrm{L}]$. Conclusion: For establishing the indirect reference intervals from the hospital records, laboratory data can be combined with information stored in clinical databases for selecting subjects fulfilling stated clinical criteria.

Key words: Indirect reference intervals, Thyrotropin, Hospital records, Non-parametric

\section{Website:}

http://nepjol.info/index.php/AJMS

DOI: 10.3126/ajms.v8i3.16648

E-ISSN: 2091-0576

P-ISSN: $2467-9100$

\section{INTRODUCTION}

Reference intervals serve as the foundation for the interpretation of medical laboratory data assisting in clinical decision making. ${ }^{1}$ The International Federation of Clinical Chemistry (IFCC) recommends that each laboratory should timely produce its own reference intervals. ${ }^{2}$ In many circumstances, the preeminent reference intervals are the subject-based ones, in the face of the ubiquitous exploitation of population-based reference values. Some of the most important conditions to be met for obtaining legitimate reference intervals are the lucid characterization of reference individuals (both healthy individuals and diseased patients); similitude of the patients with the reference individuals; transparency regarding the settings of sample collection, processing and analysis; use of clinically relevant parameter, apart from other issues related to quality control. ${ }^{1}$ However, for a hospital clinical chemistry laboratory that is obliged to produce reference intervals for all biochemical analytes on a regular basis, stringently 
meeting all the above criteria usually turns out to be an arduous and tedious task, costing a surplus amount of finance and logistics. Therefore, the possibility of setting up the reference intervals form hospital laboratory records is a plausible approach to a large extent. ${ }^{3}$

Thyrotropin or thyroid stimulating hormone (TSH) is a pituitary tropic hormone; is the most important preliminary biochemical marker of thyroid dysfunctions. Hence, the reference intervals of this hormone is unarguably indispensable for a clinical decision making exercise for thyroid diseases. Evidence has it that the distribution of serum TSH in the population is significantly skewed form the normal symmetric one. ${ }^{4}$ This obviously calls for a nonparametric method for determination of its reference range. Kouri et al. ${ }^{5}$ attempted to establish indirect reference intervals for hematological parameters; and in a separate study, Inal et al., ${ }^{6}$ for thyrotropin from hospital laboratory database.

The objective of the current study was to determine the indirect reference intervals for serum thyrotropin from the hospital records of individuals visiting a tertiary care center, for the total participants, and different subgroups of gender, age, and ethnicity; by an indirect, non-parametric method. Additionally, our aim was to identify the statistical strategy that can be employed to determine the reference intervals for this hormone that best agree with the those provided by the test kit suppliers.

\section{MATERIALS AND METHODS}

We used a hospital-record based, observational, crosssectional study design. After obtaining clearance from institutional ethical committee, we collected data of serum thyrotropin levels from the hospital records of participants who underwent this test in the Central Clinical Laboratory, College of Medical Sciences and Teaching Hospital Bharatpur, Chitwan, Nepal within three years, from July 2012 to June 2015. All the individuals, irrespective of their diagnoses of thyroid diseases (hypothyroidism or hyperthyroidism) and other possible co-morbid conditions, were included in our study. Apart from the primary variable of interest, i.e., serum thyrotropin (TSH), demographic variables of the participants (gender, age and ethnicity) were also recorded. The serum thyrotropin levels were measured in Maglumi-2000 Biochemical Analyzer, CLIA (Sandwich Immunoluminometric Assay). As mentioned in the test kits, the reference intervals for this hormone was 0.3-4.5 mIU/L. Serum thyrotropin levels of the study participants were categorized into different subgroups of age ( $<30$ years, $30-40$ years, $40-50$ years, $50-60$ years and $\geq 60$ years), ethnicity (Indo-Aryan, Tibeto-Burman, Newar, and Miscellaneous), besides two gender groups, i.e., males and females.

\section{Statistical Analysis}

Data on serum thyrotropin and other demographic variables were first entered in Microsoft Excel 2007. After excluding the repeat TSH values and THS values outside of the detection limit of the instrument ( $\geq 100 \mathrm{mIU} / \mathrm{L}$ or $\leq 0.01 \mathrm{mIU} / \mathrm{L}$ ) for any participant, data was finally entered and analysed in SPSS (Statistical Package for Social Sciences) version 20. Normality of distribution of serum thyrotropin (TSH) was tested using Kolmogorov-Smirnov Test, which showed the distribution to be significantly right-skewed. As such, a non-parametric approach was used to calculate the indirect reference interval for serum TSH. Outliers were detected and removed using Tukey's method. ${ }^{7}$ In this method, outliers were defined as TSH values between: TSH more than third quartile plus 1.5 times interquartile range and TSH less than first quartile minus 1.5 times the interquartile range. Tukey's method was applied both in natural log-transformed and non-transformed TSH values. Next, reference interval for TSH was determined by taking the $2.5^{\text {th }}$ Centile and $97.5^{\text {th }}$ Centiles for total participants and participants in each subgroup of demographic variables (gender, age and ethnicity). Bootstrapping was done to calculate the $90 \%$ confidence interval for both the limits of the reference intervals.

\section{RESULTS}

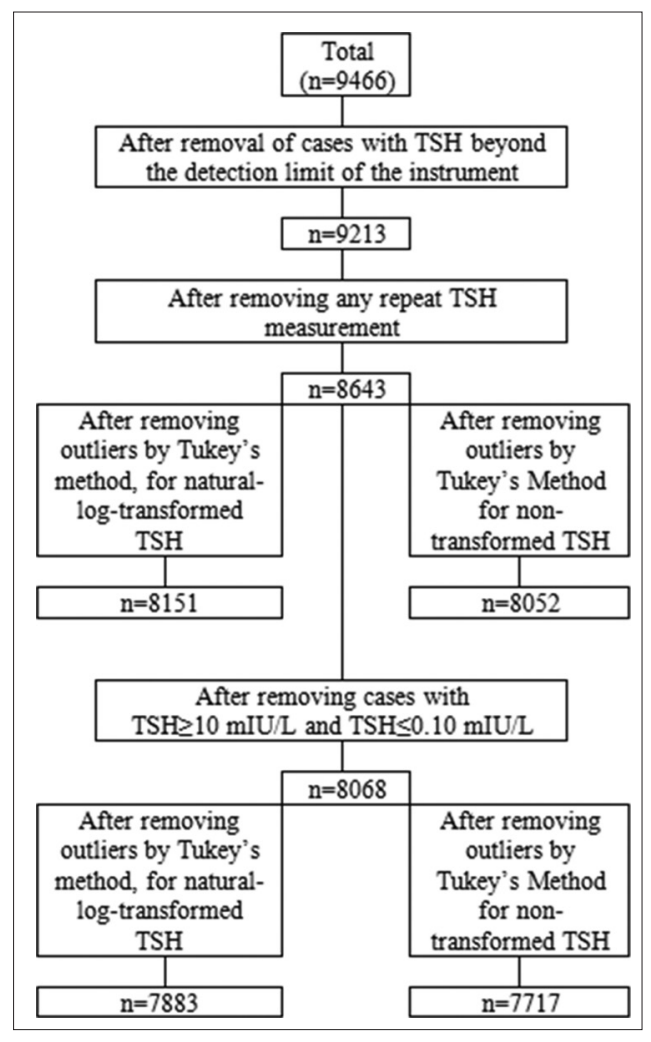

From the data registry of central clinical laboratory of the hospital, a total of 9466 measured TSH values were 
obtained. Of these, 253 TSH values were discarded as they represented those outside of the detection limit for the instruments and didn't represent the true TSH values. Next, of the remaining 9213, 570 TSH values were again omitted as they were the repeated ones (only a single, initially measured TSH value for each participant was used in the analysis). Again, from the 8643 cases, those with TSH values within the range of $0.1-10 \mathrm{mIU} / \mathrm{L}$ were included, discarding the rest. Finally, outliers were removed based on Tukey's methods (with and without natural $\log$ transformation of the TSH) from both the types of cases (with TSH in the ranges $0.02-98.8 \mathrm{mIU} / \mathrm{L}$ and 0.1-10 mIU/L) (Table 1).

Reference ranges for TSH (mIU/L) were determined for different scenarios, as depicted in the tables 1, 2 and 3 .
For each scenario, reference ranges of this hormone were established for total participants and different subgroups of gender, age and ethnicity. For each included range of TSH of the total participants (TSH: 0.02-98.8 or 0.102-9.99 mIU/L), non-parametric (indirect) reference intervals for this hormone was found to vary considerably depending on several factors, (a) whether outliers have been removed or not, or (c) whether TSH values were natural-log transformed or not transformed prior to applying Tukey's method of outlier detection (Table 1-3).

Owing to the significant right skewness of the distribution of TSH values, no single method described above could give both the lower and upper limit of the reference interval. The best possible reference intervals of serum thyrotropin from the hospitalized patients were best

\begin{tabular}{|c|c|c|c|c|c|c|}
\hline \multirow[t]{2}{*}{ Statistical strategies } & \multicolumn{3}{|c|}{ TSH (0.02-98.8 mlU/L) (Method-1) } & \multicolumn{3}{|c|}{ TSH (0.102-9.99 mlU/L) (Method-2) } \\
\hline & $\mathbf{N}$ & $\begin{array}{l}2.5^{\text {th }} \text { Centile } \\
(90 \% \mathrm{Cl})\end{array}$ & $\begin{array}{l}97.5^{\text {th }} \text { Centile } \\
(90 \% \mathrm{Cl})\end{array}$ & $\mathbf{N}$ & $\begin{array}{l}2.5^{\text {th }} \text { Centile } \\
(90 \% \mathrm{Cl})\end{array}$ & $\begin{array}{l}97.5^{\text {th }} \text { Centile } \\
(90 \% \mathrm{Cl})\end{array}$ \\
\hline Outliers not removed & 8643 & $\begin{array}{c}0.08 \\
(0.06-0.09)\end{array}$ & $\begin{array}{c}12.85 \\
(11.84-14.34)\end{array}$ & 8068 & $\begin{array}{c}0.23 \\
(0.22-0.25)\end{array}$ & $\begin{array}{c}7.50 \\
(7.30-7.72)\end{array}$ \\
\hline $\begin{array}{l}\text { Outliers removed (Tukey's method, } \\
\text { natural-log TSH) }\end{array}$ & 8151 & $\begin{array}{c}0.31 \\
(0.30-0.33)\end{array}$ & $\begin{array}{c}9.77 \\
(9.46-10.32)\end{array}$ & 7883 & $\begin{array}{c}0.35 \\
(0.34-0.37)\end{array}$ & $\begin{array}{c}7.54 \\
(7.37-7.74)\end{array}$ \\
\hline $\begin{array}{l}\text { Outliers removed (Tukey's method, } \\
\text { non-transformed TSH) }\end{array}$ & 8052 & $\begin{array}{c}0.06 \\
(0.05-0.08)\end{array}$ & $\begin{array}{c}6.04 \\
(5.97-6.12)\end{array}$ & 7717 & $\begin{array}{c}0.23 \\
(0.21-0.24)\end{array}$ & $\begin{array}{c}5.81 \\
(5.75-5.90)\end{array}$ \\
\hline
\end{tabular}

\begin{tabular}{|c|c|c|c|c|c|c|}
\hline \multirow{3}{*}{$\begin{array}{l}\text { Variables } \\
\text { (subgroups) }\end{array}$} & \multicolumn{6}{|c|}{ Outlier removal (Tukey's Method) performed } \\
\hline & \multicolumn{3}{|c|}{ TSH (Non-Transformed) } & \multicolumn{3}{|c|}{ TSH (Natural log transformed) } \\
\hline & $\mathbf{N}$ & $\begin{array}{c}2.5^{\text {th }} \text { Centile } \\
(90 \% \mathrm{Cl})\end{array}$ & $\begin{array}{c}97.5^{\text {th }} \text { Centile } \\
(90 \% \mathrm{Cl})\end{array}$ & $\mathbf{N}$ & $\begin{array}{c}2.5^{\text {th }} \text { Centile } \\
(90 \% \mathrm{Cl})\end{array}$ & $\begin{array}{c}97.5^{\text {th }} \text { Centile } \\
(90 \% \mathrm{Cl})\end{array}$ \\
\hline \multicolumn{7}{|l|}{ Gender } \\
\hline Male & 1975 & $\begin{array}{c}0.05 \\
(0.04-0.07)\end{array}$ & $\begin{array}{c}5.95 \\
(5.75-6.11)\end{array}$ & 1977 & $\begin{array}{c}0.30 \\
(0.28-0.33)\end{array}$ & $\begin{array}{c}9.28 \\
(8.30-11.28)\end{array}$ \\
\hline Female & 6077 & $\begin{array}{c}0.07 \\
(0.05-0.09)\end{array}$ & $\begin{array}{c}6.07 \\
(5.98-6.14)\end{array}$ & 6174 & $\begin{array}{c}0.31 \\
(0.30-0.33)\end{array}$ & $\begin{array}{c}9.81 \\
(9.51-10.46)\end{array}$ \\
\hline \multicolumn{7}{|l|}{ Age Groups } \\
\hline$<30$ years & 1717 & $\begin{array}{c}0.19 \\
(0.13-0.24)\end{array}$ & $\begin{array}{c}5.96 \\
(5.65-6.13)\end{array}$ & 1741 & $\begin{array}{c}0.38 \\
(0.33-0.45)\end{array}$ & $\begin{array}{c}8.33 \\
(7.45-9.13)\end{array}$ \\
\hline $30-40$ years & 1673 & $\begin{array}{c}0.10 \\
(0.06-0.17)\end{array}$ & $\begin{array}{c}6.14 \\
(5.97-6.25)\end{array}$ & 1704 & $\begin{array}{c}0.41 \\
(0.37-0.45)\end{array}$ & $\begin{array}{c}9.58 \\
(8.95-10.58)\end{array}$ \\
\hline $40-50$ years & 1822 & $\begin{array}{c}0.11 \\
(0.06-0.14)\end{array}$ & $\begin{array}{c}6.12 \\
(5.95-6.29)\end{array}$ & 1869 & $\begin{array}{c}0.40 \\
(0.36-0.43)\end{array}$ & $\begin{array}{c}10.16 \\
(9.32-10.89)\end{array}$ \\
\hline $50-60$ years & 1379 & $\begin{array}{c}0.05 \\
(0.03-0.08)\end{array}$ & $\begin{array}{c}6.03 \\
(5.81-6.24)\end{array}$ & 1409 & $\begin{array}{c}0.31 \\
(0.28-0.34)\end{array}$ & $\begin{array}{c}10.68 \\
(9.71-11.82)\end{array}$ \\
\hline$\geq 60$ years & 1461 & $\begin{array}{c}0.03 \\
(0.02-0.04)\end{array}$ & $\begin{array}{c}5.99 \\
(5.74-6.20)\end{array}$ & 1428 & $\begin{array}{c}0.22 \\
(0.21-0.24)\end{array}$ & $\begin{array}{c}11.38 \\
(9.74-12.79)\end{array}$ \\
\hline \multicolumn{7}{|l|}{ Ethnic Groups } \\
\hline Indo-Aryan & 5370 & $\begin{array}{c}0.08 \\
(0.06-0.10)\end{array}$ & $\begin{array}{c}6.11 \\
(6.00-6.20)\end{array}$ & 5475 & $\begin{array}{c}0.31 \\
(0.30-0.33)\end{array}$ & $\begin{array}{c}9.89 \\
(9.45-10.49)\end{array}$ \\
\hline Tibeto-Burman & 1091 & $\begin{array}{c}0.04 \\
(0.03-0.05)\end{array}$ & $\begin{array}{c}5.94 \\
(5.78-6.13)\end{array}$ & 1081 & $\begin{array}{c}0.31 \\
(0.28-0.35)\end{array}$ & $\begin{array}{c}9.39 \\
(8.27-11.13)\end{array}$ \\
\hline Newar & 502 & $\begin{array}{c}0.06 \\
(0.02-0.13)\end{array}$ & $\begin{array}{c}5.80 \\
(5.50-5.95)\end{array}$ & 510 & $\begin{array}{c}0.30 \\
(0.26-0.40)\end{array}$ & $\begin{array}{c}10.75 \\
(8.85-12.39)\end{array}$ \\
\hline Miscellaneous & 1089 & $\begin{array}{c}0.06 \\
(0.04-0.11)\end{array}$ & $\begin{array}{c}6.02 \\
(5.83-6.26)\end{array}$ & 1085 & $\begin{array}{c}0.30 \\
(0.24-0.35)\end{array}$ & $\begin{array}{c}9.80 \\
(7.80-10.92)\end{array}$ \\
\hline
\end{tabular}




\begin{tabular}{|c|c|c|c|c|c|c|}
\hline \multirow{3}{*}{$\begin{array}{l}\text { Variables } \\
\text { (subgroups) }\end{array}$} & \multicolumn{6}{|c|}{ Outlier removal (Tukey's Method) performed } \\
\hline & \multicolumn{3}{|c|}{ TSH (Non-Transformed) } & \multicolumn{3}{|c|}{ TSH (Natural log transformed) } \\
\hline & $\mathbf{N}$ & $\begin{array}{c}2.5 t^{\mathrm{h}} \text { Centile } \\
(90 \% \mathrm{Cl})\end{array}$ & $\begin{array}{c}97.5^{\text {th }} \text { Centile } \\
(90 \% \mathrm{Cl})\end{array}$ & $\mathbf{N}$ & $\begin{array}{c}2.5^{\text {th }} \text { Centile } \\
(90 \% \mathrm{Cl})\end{array}$ & $\begin{array}{c}97.5^{\text {th }} \text { Centile } \\
(90 \% \mathrm{Cl})\end{array}$ \\
\hline \multicolumn{7}{|l|}{ Gender } \\
\hline Male & 1886 & $\begin{array}{c}0.21 \\
(0.19-0.24)\end{array}$ & $\begin{array}{c}5.64 \\
(5.42-5.79)\end{array}$ & 1909 & $\begin{array}{c}0.35 \\
(0.33-0.38)\end{array}$ & $\begin{array}{c}7.19 \\
(6.97-7.45)\end{array}$ \\
\hline Female & 5831 & $\begin{array}{c}0.23 \\
(0.22-0.25)\end{array}$ & $\begin{array}{c}5.87 \\
(5.78-5.95)\end{array}$ & 5974 & $\begin{array}{c}0.36 \\
(0.34-0.38)\end{array}$ & $\begin{array}{c}7.70 \\
(7.47-7.91)\end{array}$ \\
\hline \multicolumn{7}{|l|}{ Age Groups } \\
\hline$<30$ years & 1676 & $\begin{array}{c}0.32 \\
(0.28-0.36)\end{array}$ & $\begin{array}{c}5.65 \\
(5.46-5.96)\end{array}$ & 1707 & $\begin{array}{c}0.43 \\
(0.37-0.48)\end{array}$ & $\begin{array}{c}6.87 \\
(6.56-7.31)\end{array}$ \\
\hline $30-40$ years & 1613 & $\begin{array}{c}0.32 \\
(0.27-0.40)\end{array}$ & $\begin{array}{c}5.89 \\
(5.75-6.00)\end{array}$ & 1662 & $\begin{array}{c}0.44 \\
(0.40-0.47)\end{array}$ & $\begin{array}{c}7.41 \\
(7.01-7.79)\end{array}$ \\
\hline $40-50$ years & 1755 & $\begin{array}{c}0.30 \\
(0.23-0.36)\end{array}$ & $\begin{array}{c}5.87 \\
(5.75-5.95)\end{array}$ & 1815 & $\begin{array}{c}0.41 \\
(0.39-0.45)\end{array}$ & $\begin{array}{c}7.56 \\
(7.19-7.92)\end{array}$ \\
\hline $50-60$ years & 1311 & $\begin{array}{c}0.21 \\
(0.20-0.24)\end{array}$ & $\begin{array}{c}5.82 \\
(5.65-5.98)\end{array}$ & 1350 & $\begin{array}{c}0.35 \\
(0.33-0.38)\end{array}$ & $\begin{array}{c}8.11 \\
(7.68-8.39)\end{array}$ \\
\hline$\geq 60$ years & 1362 & $\begin{array}{c}0.17 \\
(0.15-0.19)\end{array}$ & $\begin{array}{c}5.75 \\
(5.34-5.97)\end{array}$ & 1349 & $\begin{array}{c}0.27 \\
(0.26-0.30)\end{array}$ & $\begin{array}{c}7.77 \\
(7.40-8.07)\end{array}$ \\
\hline \multicolumn{7}{|l|}{ Ethnic Groups } \\
\hline Indo-Aryan & 5157 & $\begin{array}{c}0.22 \\
(0.21-0.24)\end{array}$ & $\begin{array}{c}5.83 \\
(5.71-5.94)\end{array}$ & 5288 & $\begin{array}{c}0.36 \\
(0.34-0.38)\end{array}$ & $\begin{array}{c}7.68 \\
(7.45-7.93)\end{array}$ \\
\hline Tibeto-Burman & 1034 & $\begin{array}{c}0.23 \\
(0.20-0.28)\end{array}$ & $\begin{array}{c}5.82 \\
(5.47-5.96)\end{array}$ & 1051 & $\begin{array}{c}0.34 \\
(0.31-0.36)\end{array}$ & $\begin{array}{c}7.62 \\
(6.80-7.87)\end{array}$ \\
\hline Newar & 480 & $\begin{array}{c}0.26 \\
(0.23-0.35)\end{array}$ & $\begin{array}{c}5.65 \\
(5.33-5.88)\end{array}$ & 493 & $\begin{array}{c}0.33 \\
(0.29-0.41)\end{array}$ & $\begin{array}{c}7.93 \\
(6.63-8.52)\end{array}$ \\
\hline Miscellaneous & 1046 & $\begin{array}{c}0.23 \\
(0.20-0.24)\end{array}$ & $\begin{array}{c}5.86 \\
(5.74-6.01)\end{array}$ & 1051 & $\begin{array}{c}0.33 \\
(0.30-0.40)\end{array}$ & $\begin{array}{c}6.78 \\
(6.47-7.25)\end{array}$ \\
\hline
\end{tabular}

determined by taking two methods into account. In our case, for each included range of the TSH of the total participants (0.02-98.8 or 0.102-9.99 mIU/L), reference intervals agreeing better with those provided by the test kit suppliers were best determined by combining the two strategies that used Tukey's method for detection and removal of outliers, prior to the determination of the required reference intervals (Table 1).

As depicted in table 1, lower limit (i.e., 0.35; $0.34-0.37 \mathrm{mIU} / \mathrm{L}$ ) of the interval was best determined from the outliers-removed TSH values (using Tukey's method in the log-natural-transformed TSH). Similarly, upper limit (i.e., 5.81; 5.75-5.90 mIU/L) was determined from outliers-cleaned TSH values (using Tukey's method in non-transformed TSH). Moreover, of the two, TSH range of $0.102-9.99 \mathrm{mIU} / \mathrm{L}$ was better suited to determine the reference interval as compared to the TSH range of $0.02-98.8 \mathrm{mIU} / \mathrm{L}$ (0.35-5.81 vs. 0.31-6.04 mIU/L). The same strategy was employed for determining the best possible reference intervals of serum thyrotropin (TSH) for different subgroups of gender, age and ethnicity (Table 1-3).

By method-1, the lower limit for males was less than that for females ( 0.30 vs. $0.31 \mathrm{mIU} / \mathrm{L})$; however, upper limit for females was more than that for males ( 6.07 vs. $5.95 \mathrm{mIU} / \mathrm{L})$ (Table 2; Figure 1). Age-group wise analysis shows that the lower limit was the smallest in individuals who are more than or equal to 60 years and upper limit was the greatest in 30-40 years old individuals (Table 2; Figure 2). Similarly, ethnic group-wise analysis reveal that the lower limit was the least $(0.30 \mathrm{mIU} / \mathrm{L})$ in Newar and Miscellaneous, whereas, the upper limit was the greatest in Indo-Aryan group (6.11 mIU/L) (Table 2; Figure 3). By method-2, the lower limit for males was less than for females ( 0.35 vs. $0.36 \mathrm{mIU} / \mathrm{L})$; likewise, upper limit was the greatest in females (5.87 vs. $5.64 \mathrm{mIU} / \mathrm{L}$ ) (Table 3; Figure 1). The individuals with age greater than or equal to 60 years had the smallest lower limit $(0.27 \mathrm{mIU} / \mathrm{L})$; those with age 30-40 years had the greatest upper limit (5.89 mIU/L) (Table 3; Figure 2). Finally, lower limit was least in Newar and Miscellaneous ethnic groups $(0.33 \mathrm{mIU} / \mathrm{L})$ and upper limit was highest in Miscellaneous (5.86 mIU/L) (Table 3; Figure 3).

\section{DISCUSSION}

Determining the reference interval for any biochemical analyte from the hospital records is inherently erroneous. However, owing to the difficulties in reference interval determination using the guidelines given by IFCC, many studies have, in fact, reported alternative approaches. 


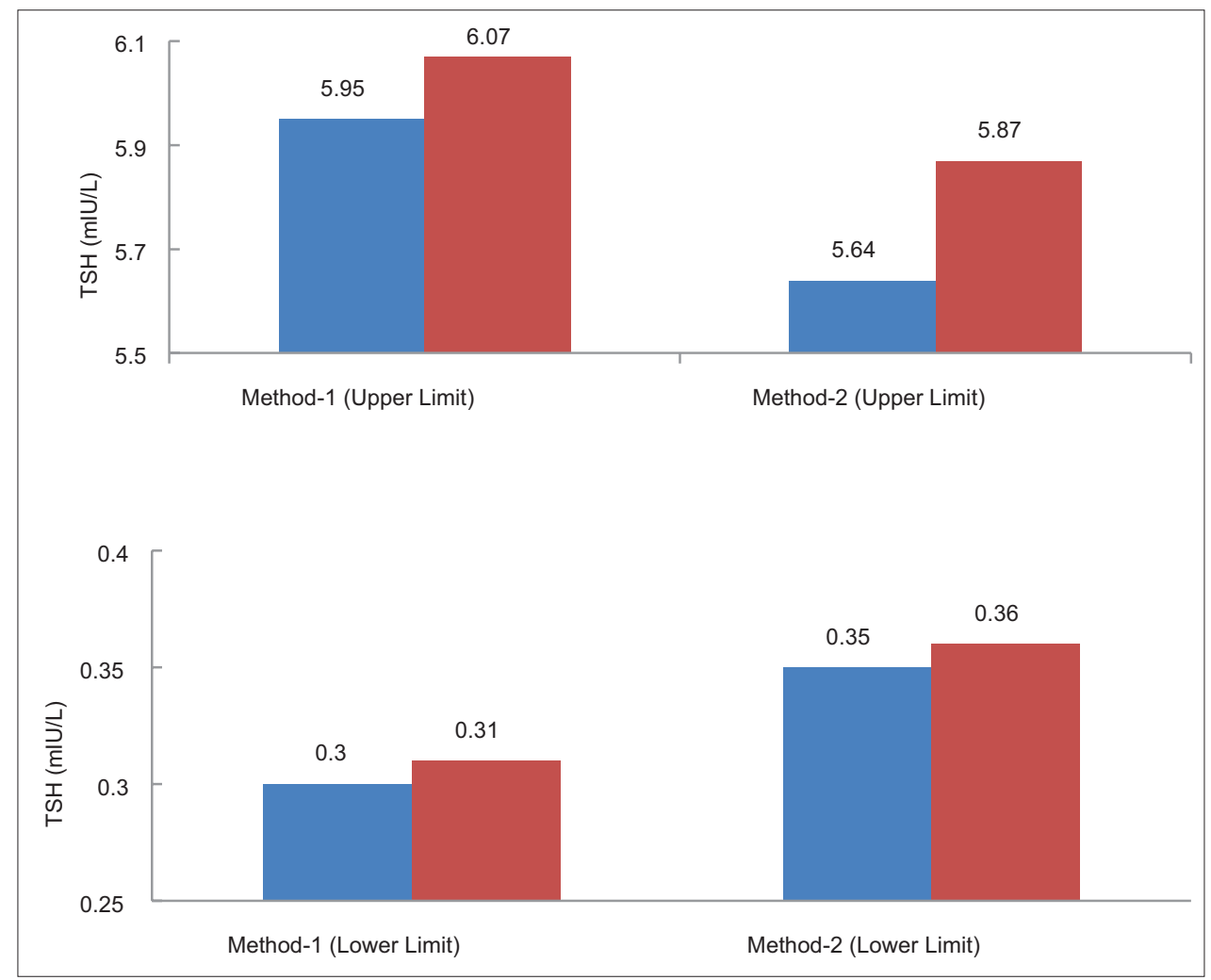

Figure 1: Lower and upper limits of TSH (mIU/L) in male (blue) and female (red) study participants by Method-1 and Method-2

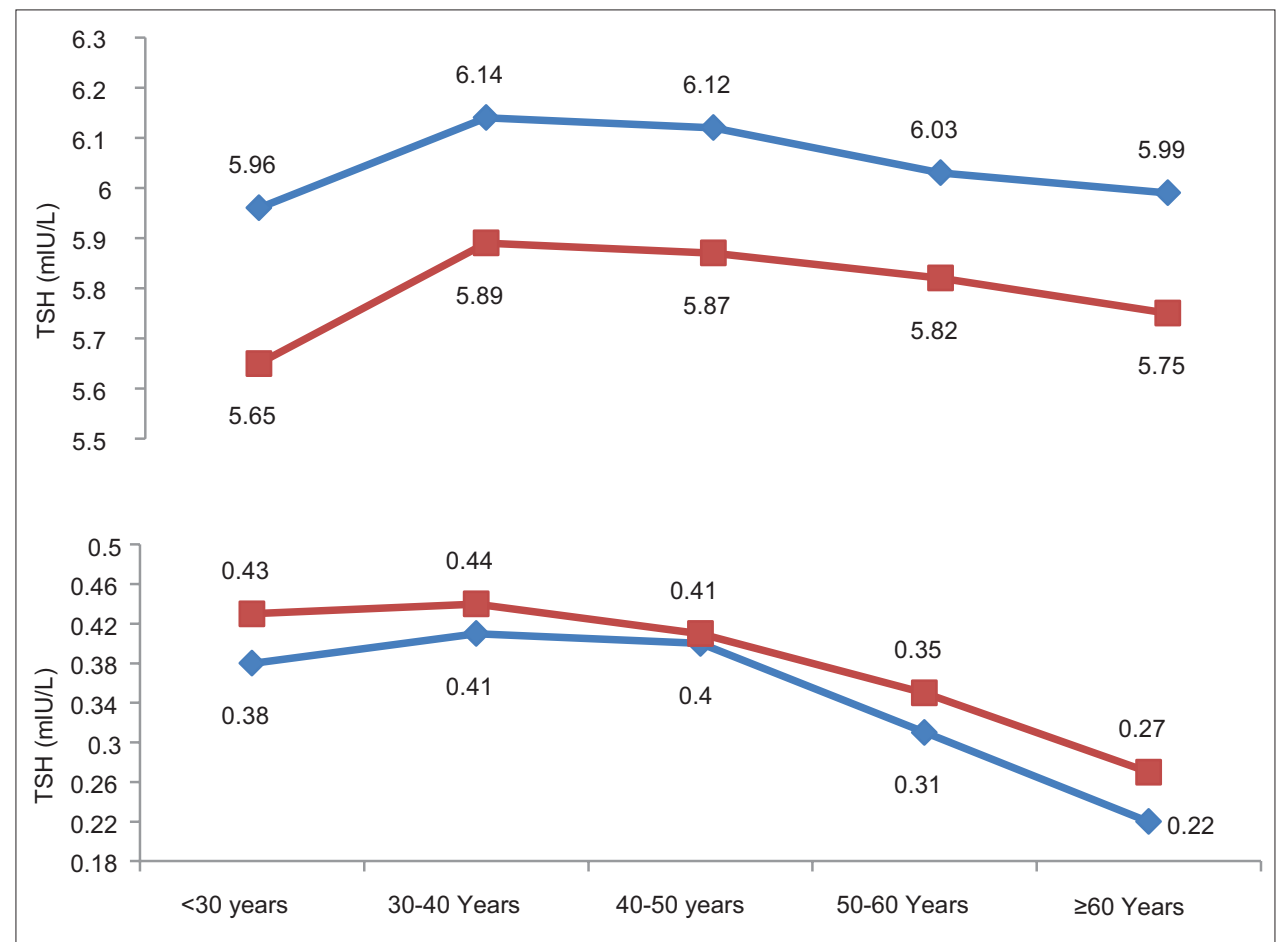

Figure 2: Lower and upper limits of TSH (mIU/L) in study participants of different age-groups by method-1 (blue) and method-2 (red)

In this study, we have attempted to determine the indirect reference intervals of serum thyrotropin from the hospital records of the patients (including healthy individuals as well as those with thyroid dysfunctions) by combining two methods of outlier detection and removal prior to the analysis. 


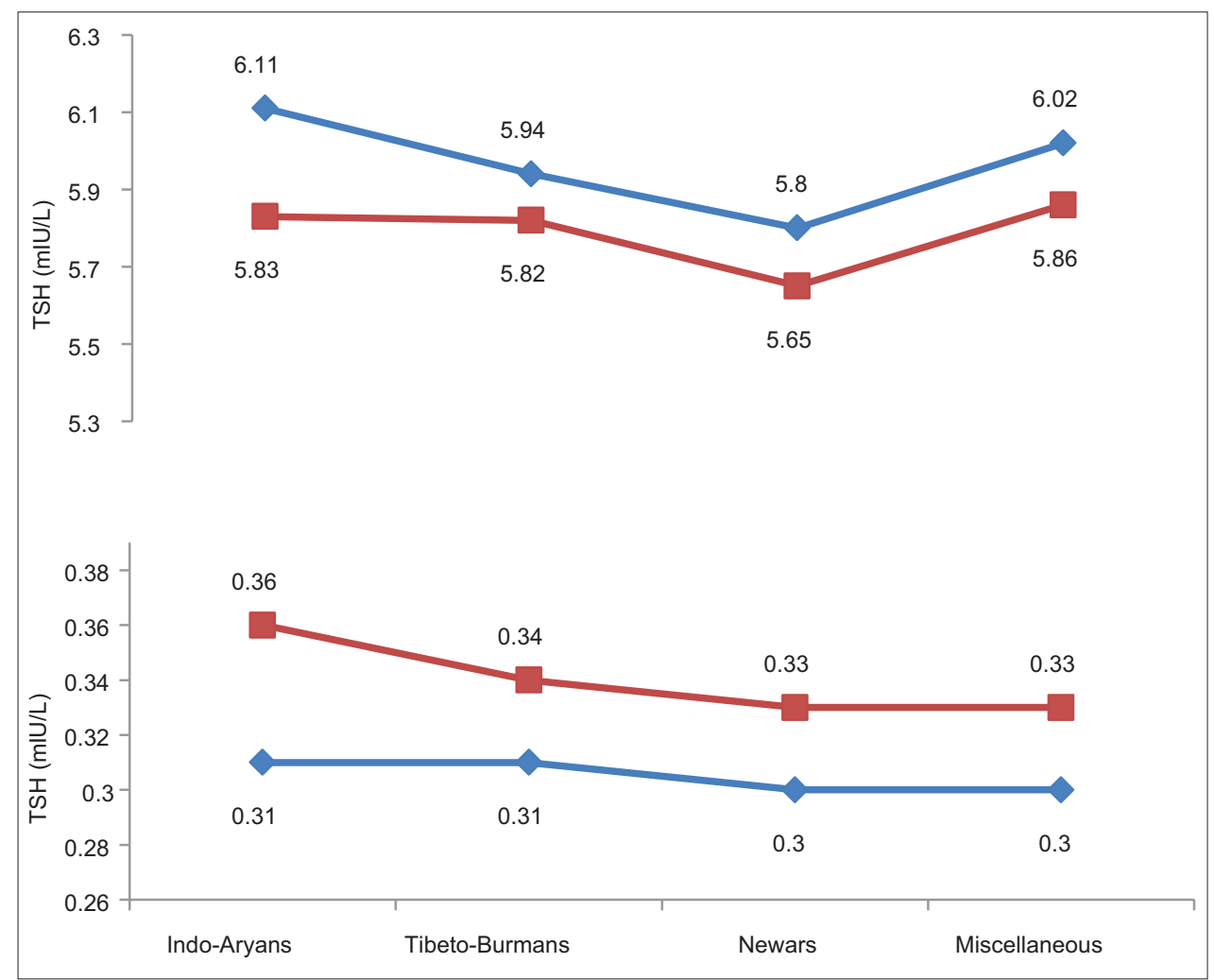

Figure 3: Lower and upper limits of TSH (mIU/L) in study participants of different ethnic-groups by method-1 (blue) and method-2 (red)

Strich et al. ${ }^{8}$ compared the reference intervals of TSH as obtained after employing different statistical strategies for data normalization, prior to the analysis. With their results, they inferred that these different normalization methods significantly vary the reference intervals.

In our study, the lower limit was best determined after removing the outliers by Tukey's method for the natural$\log$ transformed TSH values; whereas the upper limit was determined after removing the outliers by Tukey's method for the non-transformed TSH values. Additionally, similar analyses were performed after excluding the cases with TSH values $\geq 10 \mathrm{mIU} / \mathrm{L}$ and $\leq 0.1 \mathrm{mIU} / \mathrm{L}$. The results showed that the reference interval of TSH from all the participants was greater than that from the participants after excluding the TSH values beyond the defined ranges of normo-thyroid and sub-clinical thyroid dysfunctions, i.e., $0.1-10 \mathrm{mIU} / \mathrm{L}$ (Table 1).

Jensen et al. ${ }^{9}$ determined the reference intervals for serum TSH from 1512 individuals and compared them with those recommended by National Academy of Clinical Biochemistry (NACB) guidelines. The results showed that the reference interval for this hormone for the total population aged between 17-66 years was $0.58-4.07 \mathrm{mIU} / \mathrm{L}$; the values were much higher than the recommended ones.
In this study, the reference intervals for serum TSH were [0.31(0.30-0.33) to 6.04(5.97-6.12) $\mathrm{mIU} / \mathrm{L}]$ and $[0.35(0.34-$ $0.37)$ to $5.81(5.75-5.90) \mathrm{mIU} / \mathrm{L}$ for total participants and those after exclusion, respectively (Table 1).

After excluding subjects with thyroid dysfunctions, Kahapola-Arachchige et al. ${ }^{10}$ established the reference intervals for thyrotropin from the hospital repository. They compared the reference intervals of TSH in different age-groups, and found that the lower limit was more or less unswerving $(\sim 0.5 \mathrm{mIU} / \mathrm{L})$ across the age-groups. Nevertheless, the upper limit started showing acclivity from 40 years $(3.75 \mathrm{mIU} / \mathrm{L})$; up to the maximum of $5.0 \mathrm{mIU} / \mathrm{L}$ at age 90 .

In their research, Fontes et al. ${ }^{11}$ determined the age-specific reference intervals for serum TSH using 1200 reference individuals of both genders after making certain clinically relevant criteria for inclusion of the study participants. The exclusion criteria included goiter, positive thyroid peroxidase and thyroglobulin antibodies, amongst other laboratory derangements. They found the TSH levels to be increasing with age although no statistically significant difference existed between the individual subgroups. The different TSH reference intervals for the three major age groups were 0.4-4.3 mIU/L (20-59 years), 0.4-5.8 $\mathrm{mIU} / \mathrm{L}$ (60-79 years), $0.4-6.7 \mathrm{mIU} / \mathrm{L}$ ( $\geq 80$ years). 
Lewandowski ${ }^{12}$ argues that in the elderly subjects (i.e., 70 plus years), the upper normal limit of serum TSH may be as high as $6.0 \mathrm{mIU} / \mathrm{L}$.

In our study, by employing "method-1", the lower normal value for TSH showed increment from $<30$ years $(0.38 \mathrm{mIU} / \mathrm{L})$ to $30-40$ years $(0.41 \mathrm{mIU} / \mathrm{L})$ and then start decreasing as $40-50$ years $(0.40 \mathrm{mIU} / \mathrm{L}), 50-60$ years $(0.31 \mathrm{mIU} / \mathrm{L})$ and $\geq 60$ years $(0.22 \mathrm{mIU} / \mathrm{L})$. However, the upper normal value was more or less consistent (5.96-6.14 mIU/L) (Table 2; Figure 2). According to the findings of "method-2", the lower normal value varied as $<30$ years $(0.43 \mathrm{mIU} / \mathrm{L}), 30-40$ years $(0.44 \mathrm{mIU} / \mathrm{L})$, $40-50$ years $(0.41 \mathrm{mIU} / \mathrm{L}), 50-60$ years $(0.35 \mathrm{mIU} / \mathrm{L})$ and $\geq 60$ years $(0.27 \mathrm{mIU} / \mathrm{L})$. Similar to "method-1", the upper normal values were also relatively consistent (5.65-5.89 mIU/L) for "method-2" (Table 3; Figure 2).

\section{Limitations of the Study}

The obvious limitation of the study stems from the inclusion of the study participants. Since all the cases were included, irrespective of the diagnoses of thyroid dysfunctions, the present study is likely to suffer from the effects of TSH values of those individuals who are suffering from thyroid dysfunctions (hypo or hyperthyroidism) and who are under the medications for the same conditions. Although some erroneous cases were excluded using certain criteria of subclinical thyroid dysfunctions and in the process of outlier removal, the present study, in many ways, violates the guidelines given by the IFCC for the determination of reference intervals. Additionally, apart from the demographic profiles, no additional clinical information of the participants makes sources of imprecision or potential bias difficult to determine.

Evidence shows that the indirect method of reference interval calculation as done in our study has been the subject of some staid disputes as under: (i) as the populations visiting the hospitals vary from one institution to another, the indirect reference intervals produced from them are likely to vary as well, (ii) the indirect reference intervals may be quite ambiguous as their determination is largely dependent on statistical approaches. ${ }^{3}$

\section{Strengths of the Study}

The generalisability of the present study, despite its limitations, can be advocated for from the perspective of a clinical laboratory that has an obligation of having its own reference interval for any biochemical analyte apart from the tremendous labor it has to invest in the process, if the guidelines of the IFCC are to be followed by the book. Additionally, many recent studies have reported employing indirect approaches for establishing the reference intervals using the hospital records. These are not only less time consuming, but also minimize the effects of the environments in which the sample is collected and analysed. In an ideal scenario, samples from healthy population are collected outside the premises of the hospital for obtaining the reference intervals to be utilized for patients visiting the hospital.

In this regard, Solberg, ${ }^{3}$ in the editorial remarks, points out two apparent pros of establishing hospital-based reference intervals, i.e., reduction of a considerable amount of money and work by using existing data and matching of the reference values with new clinical results.

\section{CONCLUSION}

Despite many inherent and undefined sources of imprecision, indirect reference intervals of serum thyrotropin can be calculated from the hospital records using an alternative approach, as discussed in our study. The laboratory data can be combined with information stored in clinical databases for selecting subjects fulfilling stated clinical criteria. ${ }^{3}$

In the context when information in clinical record is deficient or erroneous, errors may go undetected. In this scenario, the most viable solution would be to treat the distribution of values by appropriate statistical methods. ${ }^{3}$ The combined approach as utilized in our study makes the process of reference interval calculation less erroneous in the context when the distribution of the serum thyrotropin values is significantly deviated from the normality.

\section{ACKNOWLEDGEMENT}

Record-Section, College of Medical Science and Teaching Hospital, Bharatpur, Chitwan, Nepal

\section{REFERENCES}

1. Horowitz GL. Establishment and use of reference values. In: Burtis CA, Ashwood ER, Bruns DE, editor. Tietz textbook of clinical chemistry and molecular diagnostics. Fifth ed. St. Louis, Missouri: Elsevier Inc.; 2012. p. 95-118.

2. Solberg HE. International Federation of Clinical Chemistry (IFCC), Scientific Committee, Clinical Section, Expert Panel on Theory of Reference Values, and International Committee for Standardization in Haematology (ICSH), Standing Committee on Reference Values. Approved Recommendation (1986) on the theory of reference values. Part 1 . The concept of reference values. J Clin Chem Clin Biochem. 1987 May;25(5):337-42. http://www.ncbi.nlm.nih.gov/pubmed/3612033.

3. Solberg HE. Using a hospitalized population to establish reference intervals: pros and cons. Clin Chem. 1994 Dec;40(12):2205-6. http://www.ncbi.nlm.nih.gov/pubmed/7988005.

4. Zophel K, Wunderlich G and Kotzerke J. Should we really determine a reference population for the definition 
of thyroid-stimulating hormone reference interval? Clin Chem. 2006 Feb;52(2):329-30. http://www.ncbi.nlm.nih.gov/ pubmed/16449219.

5. Kouri T, Kairisto V, Virtanen A, Uusipaikka E, Rajamaki A, Finneman $\mathrm{H}$, et al. Reference intervals developed from data for hospitalized patients: computerized method based on combination of laboratory and diagnostic data. Clin Chem. 1994 Dec;40(12):2209-15. http://www.ncbi.nlm.nih.gov/ pubmed $/ 7988006$.

6. Inal TC, Serteser M, Coskun A, Ozpinar A and Unsal I. Indirect reference intervals estimated from hospitalized population for thyrotropin and free thyroxine. Croat Med J. 2010 Apr;51(2):124-30. http://www.ncbi.nlm.nih.gov/pubmed/20401954.

7. Tukey JW. Exploratory data analysis: Addison-Wesley; 1977.

8. Strich D, Karavani G, Levin S, Edri S and Gillis D. Normal limits for serum thyrotropin vary greatly depending on method. Clin Endocrinol (Oxf). 2016 Jul;85(1):110-5. http://www.ncbi.nlm.nih. gov/pubmed/26529455.
9. Jensen $E$, Hyltoft Petersen $P$, Blaabjerg $O$, Hansen $P S$, Brix $\mathrm{TH}$, Kyvik KO, et al. Establishment of a serum thyroid stimulating hormone (TSH) reference interval in healthy adults. The importance of environmental factors, including thyroid antibodies. Clin Chem Lab Med. 2004;42(7):824-32. http://www. ncbi.nlm.nih.gov/pubmed/15327019.

10. Kahapola-Arachchige KM, Hadlow N, Wardrop R, Lim EM and Walsh JP. Age-specific TSH reference ranges have minimal impact on the diagnosis of thyroid dysfunction. Clin Endocrinol (Oxf). 2012 Nov;77(5):773-9. http://www.ncbi.nlm.nih.gov/ pubmed/22703566.

11. Fontes $\mathrm{R}$, Coeli $\mathrm{CR}$, Aguiar $\mathrm{F}$ and Vaisman $\mathrm{M}$. Reference interval of thyroid stimulating hormone and free thyroxine in a reference population over 60 years old and in very old subjects (over 80 years): comparison to young subjects. Thyroid Res. 2013 Dec 24;6(1):13. http://www.ncbi.nlm.nih.gov/ pubmed/24365659.

12. Lewandowski K. Reference ranges for TSH and thyroid hormones. Thyroid Res. 2015;8(Suppl 1):A17.

\footnotetext{
Authors Contribution:

KB- Concept and design of the study, data collection, manuscript preparation, statistical analysis and interpretation, critical revision of the manuscript;

NM- Concept and design of the study, critical revision of the manuscript, review of the study; PS- Review of the study, data collection; ST- Data collection and management, review of the study; JS-Concept and design of the study, critical revision of the manuscript; GK- Data collection and management, review of the study; RS- Data collection and management; literature review; SK- Data collection and management; literature review; ARS- Concept and design of the study, critical revision of the manuscript.

Work attributed to:

Department of Biochemistry, College of Medical Sciences and Teaching Hospital, Bharatpur, Chitwan, Nepal

Orcid ID:

Dr. Kushal Bhattarai: (D http://orcid.org/0000-0002-8603-7060

Dr. Nilu Manandhar: (1) http://orcid.org/0000-0002-5410-8805

Mr. Prabodh Shrestha: (1) http://orcid.org/0000-0001-5088-1625

Dr. Sangita Thapa: (D) http://orcid.org/0000-0001-8228-8455

Dr. Jharana Shrestha: (io http://orcid.org/0000-0002-9915-4741

Dr. Goma Kathayat: http://orcid.org/0000-0001-5768-6806

Dr. Reshma Shrestha: (1) http://orcid.org/0000-0003-3433-1185

Dr. Suman Kafle: (i) http://orcid.org/0000-0002-0858-9871

Dr. Athokpam Rajendra Singh: (1) http://orcid.org/0000-0001-7856-2255

Source of Support: None, Conflict of Interest: None.
} 